\title{
ESTIMATION OF LOCAL RECREATIONAL VALUE OF HAKGALA BOTANIC GARDEN.
}

\author{
C T Jayaratne and U A D P Gunawardene \\ University of Sri Jayewardenepura, \\ Nugegoda
}

The Botanical garden at Hakgala is one of the oldest ex-situ conservation areas in Sri Lanka. It is a unique environmental asset, nationally as well as globally, due to its conservation, recreation, historical, cultural, educational and other values.

A study was carried out in the Hakgala botanic garden to estimate its local recreational value. The economic approach used to estimate the recreational value was the travel cost method. The travel cost approach is a way to value unpriced goods. The surrounding areas were divided into concentric zones of increasing distance, which represented increasing levels of travel cost. A survey of users was conducted at the Hakgala garden to determine zone of origin, visitation rates, travel costs, and various socio economic characteristics. The data generated were used to regress visitation rates, the total travel cost and urban population fraction of each zone. With respect to multiple trips, the cost component was differentiated based on distances to particular destinations traveled. Demand curve based on visitation rates, was constructed using these data to estimate the consumer surplus, or benefits, from the site.

Estimated minimum total cost experienced by the visitors at the current entrance fee (Rs. 20.00) was Rs.6,943,520. When this amount is subtracted from the total consumer surplus (total welfare) of Rs.228,493,714 the estimated consumer surplus is Rs. $221,550,194$. This figure can be used to demonstrate the contribution of a botanical garden to the economy and to attract more funds to develop infrastructural facilities inside the garden from the government allocations.

Proceedings of the Ninth Annual Forestry and Environment Symposium 2003 of the Department of Forestry and Environmental Science, University of Sri Jayewardenepura, Sri Lanka 